\title{
Development and Validation of a Materials Preparation Model from the Perspective of Transformative Pedagogy
}

\author{
Hamed Barjesteh \\ Department of English, Science and Research Branch, Islamic Azad University, Tehran, Iran \\ E-mail: ha_bar77@yahoo.com \\ Parviz Birjandi (Corresponding author) \\ Department of English, Science and Research Branch, Islamic Azad University, Tehran, Iran \\ E-mail: pbirjand@yahoo.com \\ Parviz Maftoon \\ Department of English, Science and Research Branch, Islamic Azad University, Tehran, Iran
}

Doi:10.7575/aiac.alls.v.6n.6p.85

URL: http://dx.doi.org/10.7575/aiac.alls.v.6n.6p.85
Received: 18/06/2015

Accepted: 07/09/2015

\begin{abstract}
This study is a report on the design, development, and validation of a model within the main tenets of critical pedagogy (CP) with a hope to implement in education in general and applied linguistics in particular. To develop a transformative L2 materials preparation (TLMP) model, the researchers drew on Crawford's (1978) principles of CP as a springboard. These principles provide the theoretical framework of the ELT program in general, but they need to be adapted to the specific features of L2 materials development. To this end, Nation and Macalister's (2010) model of materials development were utilized to base different aspects of materials preparation. The newly developed model has driven 22 principles which was validated through a stepwise process. It was administered among 110 participants in 15 cities of Iran. Exploratory and confirmatory factor analyses were performed. The results indicated a high level of internal consistency and satisfactory construct validity. The TLMP model could be conducive for language policy makers, ELT professionals, materials and curriculum developers.
\end{abstract}

Keywords: Critical pedagogy, materials development, transformative model, ELT community, development, validation

\section{Introduction}

Critical language pedagogy (CLP) encompasses a diverse set of approaches in education that has alternately been referred to as participatory approach, pedagogy of inclusion, pedagogy of possibilities, emancipatory, dialogic, radical, engaged, transformative, postmodern pedagogy (Giroux, 1988; Hovey, 2004; Kincheloe, 2005; Pennycook, 1990; Shor \& Freire, 1987). It derives its doctrine from different critical theories-including queer theory, post-colonialism, postmodern, anti-racism and feminism- of the Neo-Marxist Frankfurt school as a revolt to the traditional school (Heras, 1999). The proponents of CLP believe that education is interwoven with social, cultural, political and economic construction in everyday life to be questioned and urged for progress in a society. They maintain that CLP is a new paradigm in thinking about education. This paradigm contends that education is influenced by the social structure; therefore, it can lead to the development of status quo (Kincheloe, 2008). From a CLP perspective, education is conceptualized as a "vehicle for social control, for ethnic assimilation and reproduction of privileging norms" (McLaren, 2000, p. 129).

Advocates of CP maintain that education including literacy programs foster direction of development in human beings (Shor, 1996). This framework has colored English language teaching (ELT) as confirmed by the hegemony of apolitical, asocial and cognitive-linguistic view of language (Pennycook, 1990). CP incorporates problem posing method by interrogating the received knowledge. This led students not to be the only consumer of knowledge. Freire (1970, p.77) criticized a model of language teaching what he coined "banking model". He posits that this model endeavors to "control thinking and action, leads men and women to adjust the world, and inhibits their creative power" (Freire, p. 77). He suggests the problem posing instruction with a transformative perspective that entails learners' real life issues and engages them in an open-ended process of problem solving (Larson-Freeman \& Anderson, 2011).

Drawing from L2 professional literature on transformative pedagogy, transformation refers to a paradigm shift in perspective that lead the habit of mind to be more permeable (Cranton, 2011). When CP comes to play, both transformation and action aim to change students' view (Mayo, 2004). This makes CP different from most other pedagogies because it invites learners to use their knowledge in a cycle of reflection and action (Wink, 2000). This doctrine implies that literacy program is unlikely to end in the classroom but will affect a wider society. This point of view is in line with the objectives of universities as they stand on the pedestal of teaching, research, and service. However, a large number of them depend on teaching rather than research (Gourley, 2012). To help students to be the 
transformative agents in the society, the proponents of CP suggest that the theoretical framework needs to be in constant interaction with learners' real life situation so that both knowledge and transformative action are increased (Kincheloe, 2008).

Many practitioners have endorsed the educational side of CLP and its contribution to learners' critical consciousness. Upon encroaching CLP, ELT practitioners have started to "engage themselves in an academic debate about the putative neutrality of ELT and the need to consider the social and political implications of ELT" (Cox \& Assis-Peterson, 1999, p. 434). Currently, some applied linguists (Canagarajah, 1999; Crooks, 2009; Pennycook, 1994; Phillipson, 1992) highlight the social, political, and cultural notion of CP in ELT. They maintain that ELT is culture-bound and education in $\mathrm{CP}$ endeavors to leave a transformative effect on learners by motivating them to reflect on their learning through providing a linkage between students' knowledge and their real life situation in a dialogical method, i.e., interaction between teacher and learners.

Canagarajah (2005) states that although CP as a new paradigm was introduced to the educational discourse almost two decades ago, it is practically absent from ELT context. Many authors attribute this to its lack of empirical consequences. Similarly, Ford (2014) asserts that the last few decades have seen a growing interest in CP both in ESL/EFL contexts. He argued that despite the great potential of CP, its implications have not been well acknowledged, and most of the works done have been restricted to the theoretical aspect of CLP. Pennycook (1990, p. 24) states that CP incorporates a set of ideologies that aims "not only to change the nature of schooling, but also the wider society." However, while taking a radical critical stance implies emanticipatory and transformative action (Giroux, 1988), a more practical approach particularly in an EFL context like Iran is reflected in calling materials development and classroom practices into question. Unlike many related studies (Abdollahzadeh \& Baniasad, 2010; Aliakbari \& Allahmoradi, 2012; Bruenig, 2005; Cox \& Assis-Peterson, 1999; Davari, 2011; Gafarsamar \& Davari, 2011) emphasizing the importance of democratic and oppression free education at the theoretical level, this study gains significance as it highlights the way in which ELT materials developers can apply this theory to practice.

The general dissatisfaction with the efficiency of the mainstream ELT in Iran has been discussed in an Iranian ELT context that can mostly be attributed to the centralized top-down educational management and policy. Many authors (Hayati \& Mashhadi, 2010; Maftoon, Yazdani Moghadam, Gholebostan, \& Beh-Afarin, 2010) among others criticized the EFL materials arguing that the public schools do not meet the needs of Iranian students. Due to this dissatisfaction, private English institutes in Iran use internationally marketed materials in their classroom. Reviewing the private school book series, we see western cultural norms and values are widespread in many EFL textbooks in Iran, leaving very limited room for the inclusion of local cultures and issues.

Pennycook (1990) highlights that one can conclude that language education will be better prepared to implement its underlying social, political, and cultural responsibilities if it reflects the tenets of CLP. In the ELT educational context of Iran, the market demands have led to a highly uncritical approach to language education, which is clearly revealed in the poverty of studies on incorporating a critical perspective on materials development. Now, given the crucial role of ELT materials, EFL teachers, and the rapid spread of English in Iran the need is felt to accommodate ELT materials in the EFL classroom to serve the local needs.

While a growing body of literature argues that $\mathrm{CP}$ has not yet started to creep into the practical aspect, this paper explores the applicability of CP to educational discourse to address this gap. In following this tendency, and with particular reference to the researchers' own teaching context in a second language (L2) teaching methodology classroom context of an M.A. level in Iran, this paper aims to develop and validate a transformative L2 materials development (TLMP) model with the hope to implement in the educational context of Iran. This newly developed model can help materials developers and EFL teachers incorporate its principles for developing and evaluating ELT materials.

\section{Method}

\section{1 participants}

This study adopted a stratified random sampling. The population was stratified according their level of education, type of participants, and gender. The respondents were 50 prospective EFL teachers, 45 private language institution teachers holding M.A. degrees, and 15 university instructors holding Ph. D in teaching English as a foreign language (TEFL). A total number of 110 participants, 43 males and 67 females, comprised the subject pool of the present study. Their ages ranged from 24 to 51 . Regarding their teaching experience, $80 \%$ of the participants had more than three years of classroom teaching experience.

\subsection{Sampling Procedures}

Describe With the absence of a reliable, valid, and comprehensive model to develop EFL materials within the framework of CLP in the context of Iran, this study attempted to develop and validate a transformative model in order to implement the proposed model in an L2 methodology course at M.A. level in Ayatollah Amoli University, Amol, Iran. To develop the model, the major principles of CP (Crawford, 1978) and Nation and Macalister's (2010) model of materials development were drawn as the springboard. Based on extensive review of the available literature on CP, Crawford's (1978) principles of ELT curriculum design were found to be comprehensive enough to serve as the basis of the course. The principles provided a theoretical framework for the ELT program in general, but they need to be tailored to the specific features of L2 materials development for the purpose of this study. Thus, another preliminary step to take before developing the model was to think of a framework upon which to base different aspects of materials development. To this end, the researchers drew on Nation and Macalister's (2010) model of materials development. 
More specifically, an attempt was made to classify Crawford's principles into Nation and Macalister's (2010) categories as meaningfully as possible so that it would be clear as to what should be done throughout the course. Finally, the researchers developed the TLMP model. The first draft of the proposed model comprised 22 principles reflecting the main tenets of CP. To probe the validity of the model, the principles of the developed model were put into a five-Lickert scale format questionnaire. After collecting the data, the preliminary and final validation were conducted to probe the content validity, reliability, and factor analysis of the proposed model.

\subsection{Instrumentation}

\subsubsection{TLMP Model}

To develop the model, the researchers classified Crawford (1978) principles of CP into Nation and Macalister's (2010) principles of materials development. In so doing, the literature was extensively searched with the hope of finding a transformative model for L2 materials development that could be readily used as the instrument of the present research. After a long and extensive search, the researchers became convinced of the necessity of developing a transformative L2 materials preparation (TLMP) model. Thus the TLMP model was proposed (See Appendix for the principles of the TLMP model).

2.3.2 Crawford's (1978) Principles of Curriculum Design and Nation and Macalister's (2010) Principles of Materials Development

Crawford (1978) proposed 20 principles of curriculum design informed by Freire's philosophy. The principles deal with nine dimensions: (1) purpose, (2) objectives, (3) content definition, (4) learning strategies, (5) learning materials, (6) planning, (7) teacher role, (8) student role, and (9) evaluation. Crawford's principles need to be adapted to the features of L2 materials development for the purpose of this study. Thus, the researchers drew on Nation and Macalister (2010) classification of curriculum principles. Nation and Macalister's (2010) allocate three groups for the principles of language curriculum development: (a) content and sequencing, (b) format and presentation, (c) assessment and evaluation. The first group of principles is concerned with what goes into a language course and the order in which language items should appear. The second group of principles is about to what actually happens in the classroom during learning, and the last group deals with monitoring, assessment, and, to some degree, evaluation.

After developing the model, the following stepwise process was conducted to probe the validity of the proposed model.

\section{Results and Discussion}

\subsection{In Preliminary Validation, Content Validity for the TLMP Principles}

To assure the content validity of proposed principles, five experts holding Ph.D. degrees in TEFL were asked to read the proposed principles and determine the content validity of each principle. Four indices (comprehensiveness, relevance, clarity, and wording) were assessed for each principle. The experts were asked to score each of the indices based on four-point content validity index (CVI) from 1 to 4, corresponding to poor (1), fair (2), good (3), and excellent (4), respectively. It was calculated by tallying the results of panel of experts, working independently, to evaluate the principles based on the four indices. Next, the following indices were computed: (a) item CVI, which indicated the validity for each principle, (b) scale validity index (SVI), which signified validity for the whole model; (c) inter-rater agreement, which delineated the extent to which the experts agree on the validity of the principles, and (d) comprehensiveness score, which unveiled how well the experts agreed that the principle was comprehensive. To compute the item validity index (IVI), the scores were divided into two classifications: (a) good /excellent, (b) fair/poor. The IVI for each principle (comprehensiveness, relevance, clarity, and wording) was calculated as the experts who scored the principle good or excellent. For each index, a cut-off point of 0.75 was considered as acceptable validity. The principles with IVI less than cut-off point were re-examined. What follows presents the information about the content validity index and the scale validity index for the TLMP principle:

\subsection{Content validity for items}

The item CVI for comprehensiveness was .93 for 22 principles. The corresponding index for relevance was .90 for the principles. The CVI for clarity and wording was .84 and .91 , respectively. The principles that received a score below .80 for item CVI were revised by the researchers and the experts, and some modifications were made based on consensus. After analyzing the results, three principles for comprehensiveness, four principles for relevance, five principles for clarity, and 3 principles for wording were in the unacceptable range. Based on this evaluation, the principles that did not meet the pre-assumed criteria were modified due to the lack of minimum content validity based of the judgment of the five experts. Then three other TEFL experts were asked to comments on the modified version. The modified items with score above .79 were retained as the appropriate items.

\subsection{Scale validity index}

Using the average approach, the overall SVI for comprehensiveness, relevance, clarity and wording were .88 . The interrater agreement for the four indices were .89 , respectively. The overall comprehensiveness score rated by the experts was $93 \%$. Table 1 shows the CVI for the principles of the TLMP model based on the experts' opinions. 


\begin{tabular}{|c|c|c|c|c|c|c|}
\hline \multicolumn{4}{|c|}{ Item content validity index } & \multirow{2}{*}{$\begin{array}{l}\text { Scale } \\
\text { Validity } \\
\text { index }\end{array}$} & \multirow{2}{*}{$\begin{array}{l}\text { Inter-rater } \\
\text { agreement }\end{array}$} & \multirow{2}{*}{$\begin{array}{l}\text { Comprehens- } \\
\text { iveness score }\end{array}$} \\
\hline Comprehensiveness & Relevance & Clarity & Wording & & & \\
\hline .93 & .91 & .84 & .90 & .88 & .89 & .93 \\
\hline
\end{tabular}

\subsection{Final validation: Reliability and factor analysis}

At this stage, the researchers needed to assure that the participants understood the principles proposed in the TLMP model in the way it was intended and the instrument could serve its intended purpose. To make this happen, Dornyei (2007, p. 112) suggests that a questionnaire should be administered to "a group of about 50 respondents who are in every way similar to the target population the instrument was designed for."

To pilot the principles of the proposed model, it was administered to 90 prospective EFL teacher, 60 private language school teachers, and 20 university instructors in 15 cities of Iran. The recipients were informed that their responses to the questionnaire would be an indication of their consent to take part. A number of received questionnaires were not usable because the participants had left many items blank or had skipped the demographic section. 110 questionnaires including 50 prospective EFL teachers, 45 private language school teachers, and 15 university instructors were qualified for the use. Once the data were collected from the pilot group, the data were fed to the Statistical Package for the Social Sciences (SPSS) version 20.

According to Dornyei (2007), three aspects of response patterns needed to be taken care of, that is, "missing responses or signs of misunderstanding, the range of responses elicited by each item and internal consistency" (p. 113). The questionnaires were scanned for the respondents who had clearly misunderstood the questionnaire (for instance, those agreeing with all items or with many completely opposite items) or had left many items blank ( more than an acceptable number to be replaced by neutral). The range of elicited responses by each item was checked by the SPSS software to "exclude items that are endorsed by almost every one or by almost no one" (Dornyei, p. 113). The internal consistency of the questionnaire enjoyed a reliability of .79. This reliability index is acceptable and strong in educational research (Hatch \& Lazaraton, 1991). The results are presented in Table 2.

Table 2. Reliability Coefficient for the TLMP model

\begin{tabular}{cc}
\hline Cronbach's Alpha & $\mathrm{N}$ \\
\hline .79 & 110 \\
\hline
\end{tabular}

Measuring the reliability and content validity, however, does not confirm the validity of a newly developed model. That is to say, a further step is needed to fully validate the model, which is to confirm its construct validity. In so doing a factor analysis was run. According to Pallant (2005), principal component analysis (PCA) is the most commonly used approach for the factor analysis. Therefore, PCA was picked to confirm the construct validity of the TLMP model in this research. The TLMP questionnaire makes use of a five-point Likert scale; that is, the respondents choose out of five options and score from one to five on each item. Thus, the minimum possible score is 22 and the maximum is 110 .

However, some items may be related to a single variable and can be grouped together. In other words, it may be possible to reduce the 22 items into a smaller number of factors, each covering a number of items related to the same factor. Thus, the researchers applied factor analysis in order to decide primarily which items should be eliminated from the list of expressions representing the principles for materials development and then to see if the researchers could arrange different items related to the same principles under the same category.

Prior to running the factor analysis, the assumptions had to be checked. The first assumption was the inter-correlation among the variables. To know about inter-correlation among the variables, one needs to obtain a correlation matrix by running the correlation analysis. In the case of TLMP, the value of determinant is .001 , which is larger than .00001 . According to the results displayed in the correlation matrix, none of the items were excluded because there were significant correlation among all the items and there were no muli-collinearity.

Another requirement is the factorability of the data. Thus, factor analysis was run with principal components chosen as the extraction technique. Bartlett's Test of Sphericity (BTS) and the Kaiser-Meyer-Olkin (KMO) measure of sampling adequacy help to determine the factorability of the data (Kaiser, 1970, cited in Pallant, 2005). ) Table 3 indicates the results of BTS and the KMO. The results enjoy the value of .63 and .000 . Simply put, the first null hypothesis suggesting that transformative L2 materials preparation model will not show a good internal consistency was rejected.

Table 3. BTS and the KMO measure of sample adequacy.

\begin{tabular}{lll}
\hline \multicolumn{2}{l}{ Kaiser-Meyer-Olkin measure of sample adequacy } & .632 \\
\hline Bartlett's Test of Sphericity & Approx. Chi-Square & 673.67 \\
& Df & 231 \\
& Sig. & .000 \\
\hline
\end{tabular}


Table 4 presents information about initial eigenvalues, extraction, and rotation data. Eigenvalue is the sum of squared loading for a factor. It conceptually represents the amount of variance account for by a factor. The results are presented in table 4. In this table, only the first seven components recorded eigenvalues above $1(4.05,2.52,1.62,1.59,1.39,1.36$, 1.18). These seven components explained $62.52 \%$ of the variance. The table below indicates that the first factor account for $18.44 \%$, factor $2(11.49 \%)$, factor $3(7.38 \%)$, factor $4(7.25 \%)$, factor $5(6.34 \%)$, factor $6(6.22 \%)$, and factor 7 (5.40) in all 22 variables.

Table 4. Total Variance Explained for the TLMP Principles

\begin{tabular}{|c|c|c|c|c|c|c|}
\hline \multirow[t]{2}{*}{ Component } & \multicolumn{3}{|c|}{ Initial Eigenvalues } & \multicolumn{3}{|c|}{ Extraction Sums of Squared Loadings } \\
\hline & Total & $\begin{array}{l}\% \\
\text { Variance }\end{array}$ & Cumulative $\%$ & Total & $\%$ of Variance & Cumulative $\%$ \\
\hline 1 & 4.057 & 18.442 & 18.442 & 4.057 & 18.442 & 18.442 \\
\hline 2 & 2.527 & 11.489 & 29.930 & 2.527 & 11.489 & 29.930 \\
\hline 3 & 1.624 & 7.384 & 37.314 & 1.624 & 7.384 & 37.314 \\
\hline 4 & 1.594 & 7.247 & 44.561 & 1.594 & 7.247 & 44.561 \\
\hline 5 & 1.396 & 6.347 & 50.907 & 1.396 & 6.347 & 50.907 \\
\hline 6 & 1.369 & 6.223 & 57.130 & 1.369 & 6.223 & 57.130 \\
\hline 7 & 1.187 & 5.396 & 62.526 & 1.187 & 5.396 & 62.526 \\
\hline 8 & .971 & 4.415 & 66.941 & & & \\
\hline 9 & .951 & 4.324 & 71.265 & & & \\
\hline 10 & .843 & 3.834 & 75.099 & & & \\
\hline 11 & .777 & 3.531 & 78.630 & & & \\
\hline 12 & .679 & 3.085 & 81.715 & & & \\
\hline 13 & .612 & 2.781 & 84.496 & & & \\
\hline 14 & .553 & 2.515 & 87.011 & & & \\
\hline 15 & .539 & 2.451 & 89.462 & & & \\
\hline 16 & .486 & 2.210 & 91.671 & & & \\
\hline 17 & .440 & 1.999 & 93.670 & & & \\
\hline 18 & .385 & 1.750 & 95.421 & & & \\
\hline 19 & .357 & 1.625 & 97.045 & & & \\
\hline 20 & .286 & 1.298 & 98.343 & & & \\
\hline 21 & .195 & .888 & 99.231 & & & \\
\hline 22 & .169 & .769 & 100.000 & & & \\
\hline
\end{tabular}

Often running KMO, many components are extracted. Thus, it is of great significance to look at the change (elbow) in a Scree Plot (Pallant, 2005). Only component above this point are retained. The results are presented in Figure 1.

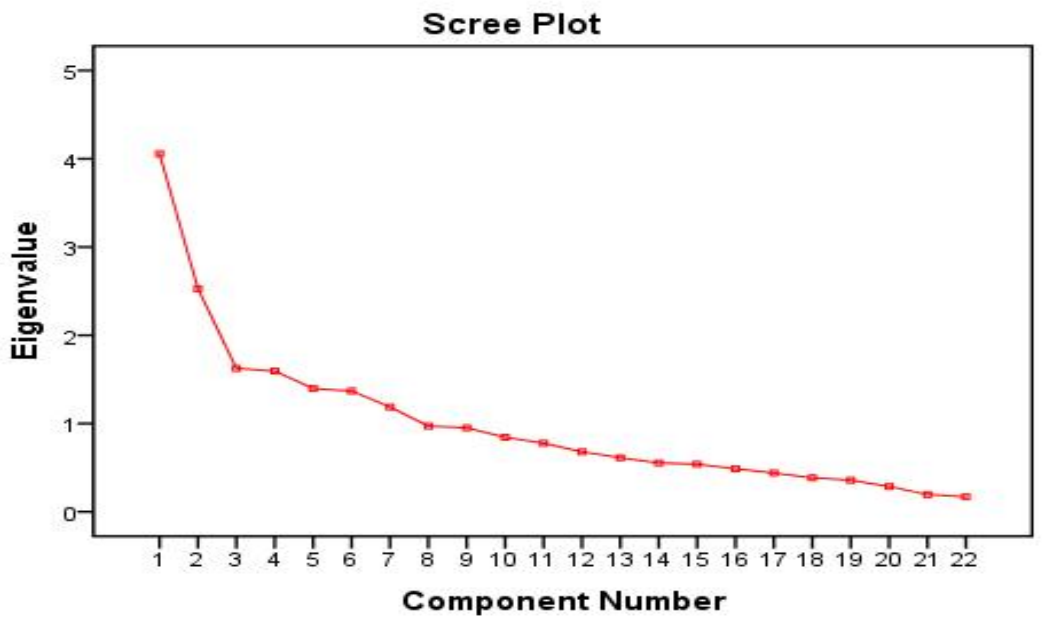

Figure 1. Scree plot of the Eigenvalues for a factor analysis on the TLMP principles

Since in the extraction procedure the eigenvalue was set at 1 and above, the extract components have eigenvalue greater than 1. Figure 1 indicates only the first seven components qualify for this point of view. This means that the seven components explained 62.5 percent of the whole variance. Thus, it is possible to reduce the original 22 principles to seven and lose only $37.5 \%$ of the information. An analysis of the ScreePlot disclosed a clear break after the third component. Using the Catell's (1966) ScreePlot, it was confirmed to keep three components for the further analysis.

To help identifying the factors, rotated component matrix was conducted. Table 5 determines what the components represent. 


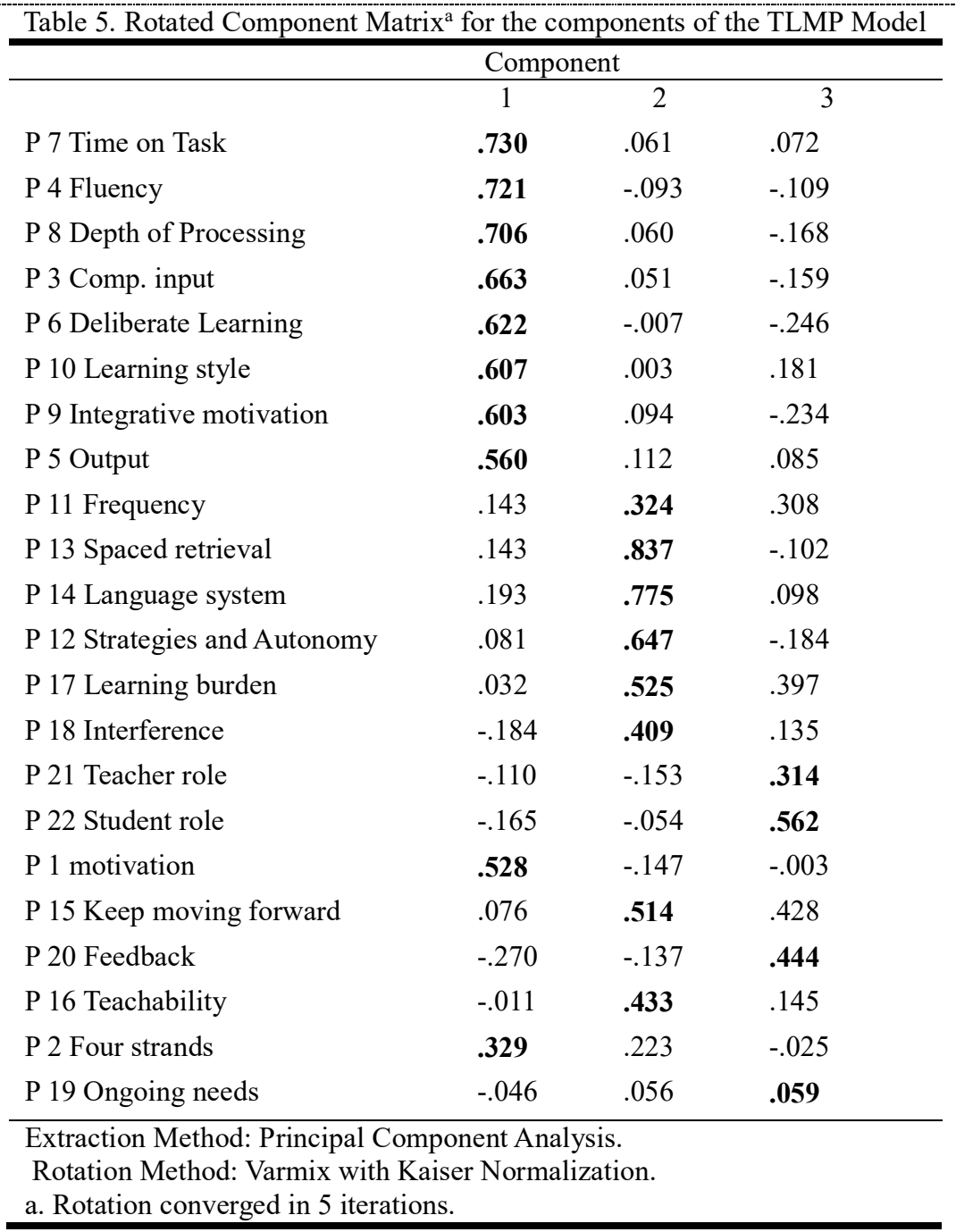

As table 5 demonstrates, component 1 encompasses principles 7,4,8,3,6,10,9,5,1,2. This set of principles is labeled format and presentation. Component 2 encompasses principles 11, 13, 14, 12,17,18,15,16. This set of principles is labeled content and sequencing. Component 3 encompasses principles 21,22,20,19. This set of principles is labeled monitoring and assessment. The components and their corresponding principles are summarized in Table 6 .

Table 6. Components and their corresponding principles

\begin{tabular}{rll}
\hline Components & Principles \\
\hline 1. & Format and presentation & $7,4,8,3,6,10,9,5,1,2$ \\
2. & Content and sequencing & $11,13,14,12,17,18,15,16$ \\
3. & Monitoring and assessment & $21,22,20,19$ \\
\hline
\end{tabular}

The three factor solution explained $37.5 \%$ of the variances with component 1 contributing 17\%, component $211.75 \%$, and component 3 contributing $8.5 \%$. It should be noted that since items with loading factors below 3 were ignored, the number of items in the questionnaire was confirmed to 22 principles. Therefore, the final validated version of the TLMP model was used for the main study.

The TLMP model is in line with Aghagolzadeh and Davari (2012) who strongly believe in empowering learners to make them the agent of transformation in the local and global arenas and reducing the cultural and social implications of English in a country such as Iran. They suggest bringing CP in to play as an alternative approach in ELT. However, they did not propose a practical guideline in order to apply the principles of CP into EFL classroom in Iran. It is also in line with a number of studies (Akbari, 2008; Aliakbari and Faraji,2011; Kumaradivelu, 2001) among others provide some useful suggestions for introducing CP into ELT classrooms, but these suggestions are still very broad without a practical framework to be applied in an EFL classroom. The proposed model contradicts with the findings of (Baladi, 2007; Gore, 1993; Kanpol, 2009; Sarroub \& Quadros, 2015) who consider CP as a critical educational theory, which is restricted at the theoretical level. Likewise, Pennycook (2001) believes that CP has been its inclination to "remain at the level of grand theorizing rather than pedagogical practice" (p. 130). Similarly, Johnson (1999) makes the same point arguing that $\mathrm{CP}$ is not enough "to capture the complex essence of teaching especially of EFL/ESL" (p. 564). Put 
differently, they believe that there is no room for the practical aspect of $\mathrm{CP}$ in the classroom discourse. The same critics might level toward the newly-developed model. Such a claim can be justified by the promising findings of the present study. Thus the proposed model suggests that one should avoid jumping to this conclusion that CP is only at the theoretical level and devoid applicability.

\section{Conclusion}

The pedagogical implication of CLP in education, in general, and applied linguistics in particular, led the evolution of critical viewpoint toward ELT industry. While there is a body of literature that considers the theory of CP, Shor (1996) and Sweet (1998) among others assert that there is less literature that addresses the ways in which EFL/ESL teachers and materials developers apply this theory in practice. Some authors like Kumaradivelu (2001) have attempted to present some guidelines for the post-method learners, teachers and teacher educator, but still some of these guidelines might not be very practical. In a similar vein, Akbari (2008) provides some useful suggestions for introducing CP into ELT classrooms, but these suggestions are still very broad without a practical framework to be applied in the classroom. Similarly, Aliakbari and Faraji (2011) recommend the application of CP in ELT classrooms, but they did not provide practical guidelines/principles for implementing this theoretical underpinning of CP in a classroom.

To address the gap, the present study was conducted as a preliminary step to develop and validate a transformative model for materials development. The proposed model has driven 22 principles that reflect students' real life situation in a dialogical method. This model aimed to foster learners' critical awareness, and critical consciousness, as well as help them become critical reflective by a linkage between theory and practice so that they find the pedagogical application. The model considers teaching as a cycle of reflection and action by embracing learners' critical needs analysis. The TLMP model suggests that critical ELT materials should co-built around problem posing by inviting learners examine the course content from the practical context of the classroom. It highlights that as much as possible should be spent focusing on reflective task to foster learners' intellectual ability. ELT materials should integrate both social development and language skill development to aid students surpasses the understanding of the texts. In addition, the language focus should speed up both collective social transformation and cognitive development, and learners should have an opportunity to work with materials in the ways that most suit their culture, society, and learning style. The model suggests that both students' critical language awareness and their linguistic skills should be evaluated through selfassessment and dynamic assessment. Students are active decision makers who participate in assessing their performance. Materials should consider teacher as a coordinator, a co-learner, and a problem poser. The TLMP model was developed and validated in an educational context of Iran with the hope to implement in the ESL/EFL context.

This model aimed to develop learners' critical consciousness. Many authors believe that CP is an ivory tower in the EFL/ESL contexts. Gore (1993) criticizes CP as it lacks applicability. She maintains that CP offers too little strategies to use in practice. Thus, she considers CP as an educational theory rather than pedagogy. Keesing-Styles (2003) postulates that critical theorists provide little account for what attempts are made within their classrooms to implement the principles of CP that they espouse. Similar criticism might also level against the newly developed model. Such criticism might be justified to this claim that "one cannot give the ten steps for a critical pedagogy" (Kanpol, 1998, p. 3). Each situation is different. CP struggles against any formulaic enterprise in which learners are regarded as passive recipients of deposits of prescribed materials. Therefore, the main feature of the TLMP model is that it is dynamics of how CP materials can be developed. The TLMP model could pave the ground for the local materials developers and EFL teachers as a touchstone to develop and adapt ELT materials in a way that gears to the learners' needs, culture, society, and learning style. However, teachers should plan for the possible risks and difficulties involved.

\section{References}

Abdollahzadeh, E., \& Baniasad, S. (2010). Ideologies in the imported English textbooks: EFL learners and teachers' awareness and attitude. Journal of English Language Teaching and Research, 53 (217), 1-17.

Aghagolzadeh, F., \& Davari, H. (2012). The rationale for applying critical pedagogy in expanding circle countries: The case of Iran. Journal of Language Teaching and Research, 5(3), 823-828.

Akbari, R. (2008). Transforming lives: Introducing critical pedagogy into ELT classrooms. ELT Journal, 62(3), 276283. doi: $10.1093 /$ elt/cen025

Aliakbari, M., \& Allahmoradi, N. (2012). On Iranian school teachers' perceptions of the principles of critical pedagogy. International Journal of Critical Pedagogy, 4(1), 154 -171.

Aliakbari, M., \& Faraji, E. (2011, September). Basic principles of critical pedagogy. Paper presented at international conference of economics development \& research, Retrieved from www.ipedr.com.

Baladi, N. (2007). Critical pedagogy in the ELT industry: Can a socially responsible curriculum find its place in a corporate culture? (Unpublished master's thesis). McGill University, Montreal, Canada.

Bruenig, M. (2005). Turning experiential education and critical pedagogy theory into practice. Journal of Experiential Education, 28(2), 106-122.

Canagarajah, A. S. (1999). Resisting linguistic imperialism in English teaching. Oxford: Oxford University Press.

Canagarajah, A. S. (2005). Critical pedagogy in L2 learning and teaching. In E. Hinkel (Ed.), Handbook of research in second language teaching and research (pp 931-951). Mahwah, NJ: Lawrence Erlbaum. 
Catell, R. B. (1966). The scree test for the number of factors. Multivariate Behavioral Research, 1, $245-276$.

Cox, M. I. P., \& Assis-Peterson, A. A. D. (1999). Critical pedagogy in ELT: Images of Brazilian teachers of English. TESOL Quarterly, 33(1), 433-484. doi: 10.5539/elt.v5n2p101

Cranton, P. (2011). A transformative perspective on the scholarship of teaching and learning. Higher Education Research and Development, 30, 75-86.

Crawford, L. M. (1978). Paulo Freire's philosophy: Derivation of curricular principles and their application to second design (Unpublished doctoral dissertation). University of Minnesota. United States.

Crooks, G. (2009). The practicality and relevance of second language critical pedagogy. Language Teaching, 1(16), 116. doi:10.1017/S026144480 9990292

Davari, H. (2011). Linguistic imperialism or global understanding: ELT in globalization from an Iranian Perspective (Unpublished master's thesis). Tarbiat Modares University, Tehran, Iran.

Dornyei, Z. (2007). Research methods in applied linguistics. New York, NJ: Oxford University Press.

Ford, D. R. (2014). A critical pedagogy of ineffability: Identity, education and the secret life of whatever. Educational Philosophy and Theory, 46(4), 380-392. doi: 10. 1080/00131 857. 2013.779218

Freire, P. (1970). Pedagogy of the oppressed. New York, NY: Continuum.

Ghaffar Samar, R., \& Davari, H. (2011). Liberalist or Alarmist: Iranian ELT Community's Attitude to Mainstream ELT vs. Critical ELT. TESOL Journal, 63(5), 63-91.

Giroux, H. A. (1988). Teachers as intellectuals: Towards a critical pedagogy of learning. South Hadley, MA: Bergin \& Garvey.

Gore, I. M. (1993). The struggle for pedagogies: Critical and feminist discourses as regimes of truth. New York: Routledge.

Gourley, B. (2012). Higher education as a force for societal change in the twenty-first century. In L. McIlrath, A. Lyons \& R. Munck (Eds.), Higher education and civic engagement: Comparative perspectives (pp. 31-40). New York, NY: Palgrave Macmillan.

Hatch, E., \& Lazaraton, A. (1991). The research manual: Design and statistics for applied linguistics. Boston: Heinle \& Heinle.

Hayati, A. M., \& Mashhadi. A. (2010). Language planning and language-in-education policy in Iran. Language Problems and Language Planning, 34(1), 24-42.

Heras, A. I. (1999). Taking action with family and community members: Critical pedagogy as a Frame work for educational change. In Z. Cline \& J. Necochea (Eds.), Advances in confluent education. Stanford, CT: JAI Press.

Hovey, R. (2004). Critical pedagogy and international studies: Reconstructing knowledge through dialogue with the subaltern. International Relations, 18(2), 241-254.

Kanpol, B. (1998). Critical pedagogy for beginning teachers: The movement from despair to hope. Online Journal of Critical Pedagogy, 2(1). Retrieved from http://users.monash.edu.au/ dzyngier/

Kanpol, B. (2009). Critical pedagogy for beginning teachers: The movement from despair to hope. Retrieved from: http://users.monash.edu.au/ dzyngier/Critical\%20Pedagogy\%20For\%20Beginning\%20Teachers\%20Barry

$\%$ 20Kanpol.htm

Keesing-Styles, L. (2003). The relationship between critical pedagogy and assessment in teacher education. The Journal of Radical Pedagogy, 5(1), 1-20. doi: 10.1177/105382590502800205

Kincheloe, J. L. (2005). Critical pedagogy primer. New York, NY: Peter Lang Publishing.

Kincheloe, J. L. (2008). Critical pedagogy primer (2nd ed.). New York, NY: Peter Lang.

Kumaravadivelu, B. (2001). Toward a post method pedagogy. TESOL Quarterly, 35(4), 537-560. doi: 10.2307/3588427

Larson-Freeman, D., \& Anderson, M. (2011). Techniques and principles in language teaching. Oxford: Oxford University Press.

Maftoon, P., Yazdani Moghadam, M., Gholebostan, H., \& Beh-Afarin, S. R. (2010). Privatization of English Education in Iran: A Feasibility Study. The Electronic Journal for English as a Second Language, 13(4), 1-13.

Mayo, P. (2004). Liberating praxis: Paulo Freire's legacy for radical education and politics. Dordrecht, the Netherlands: Sense Publishers

McLaren, P. (2000). Paulo Freire's pedagogy of possibility. In S. Steiner, H. M. Krank, P. McLaren, \& R. E. Bahruth (Eds.), Freirean pedagogy, praxis and possibilities: Projects for the new millennium (pp. 1-21). New York, NY: Falmer Press.

Nation, I. S. P., \& Macalister, J. (2010). Language curriculum design. New York, NY: Routledge.

Pallant, J. (2005). SPSS survival manual: A step by step guide to data analysis using SPSS for windows (2nd ed.). Maidenhead: Open University Press. 
Pennycook, A. (1990). Critical pedagogy and second language education. System, $18(3)$, 303-314.

Pennycook, A. (1994). The Cultural politics of English as an international language. London, Longman.

Phillipson, R. (1992). Linguistic imperialism. Oxford: Oxford University Press.

Sarroub, L. K., \& Quadros, S. (2015). Critical pedagogy in the classroom discourse. In M. Bigelow \& E. K. Johanna (Eds.), The Routledge handbook of educational linguistics (pp. 252-260). New York \& Abingdon.

Shor, I. (1996). When students have power: Negotiating authority in a critical pedagogy. Chicago: The University of Chicago Press.

Shor, I., \& Freire, P. (1987). What is the "dialogical method" of teaching? Journal of Education, 169(3), 11-31.

Sweet, S. (1998). Practicing radical pedagogy: Balancing ideals with institutional constraints. Teaching Sociology, 26, $100-111$.

Wink, J. (2000). Critical pedagogy: Notes from the real world. New York, NY: Longman.

\section{Appendix}

Principles of transformative L2 materials preparation (TLMP) model

\begin{tabular}{|c|c|}
\hline $\mathbf{A}$ & FORMAT AND PRESENTATION \\
\hline Motivation & $\begin{array}{l}\text { ELT materials should motivate students to reflect on their learning by linking their } \\
\text { knowledge to their real life situation in a dialogical method, interaction between teacher and } \\
\text { learners. }\end{array}$ \\
\hline Four strands & $\begin{array}{l}\text { ELT materials have learners focus on how to make meaning by incorporating their } \\
\text { socioeconomic status. }\end{array}$ \\
\hline $\begin{array}{l}\text { Comprehensible } \\
\text { input }\end{array}$ & $\begin{array}{l}\text { Materials should help the learners become critical reflective by providing comprehensible } \\
\text { receptive activity in both listening and reading through discussion. }\end{array}$ \\
\hline Fluency & $\begin{array}{l}\text { ELT materials should make use of discussion through cultural and political topic of great } \\
\text { concern to participants. }\end{array}$ \\
\hline Output & $\begin{array}{l}\text { Critical ELT materials are co-built around problem posing by inviting learners examine the } \\
\text { course content from the practical context of the classroom in both speaking and writing. }\end{array}$ \\
\hline Deliberate learning & $\begin{array}{l}\text { Materials should foster an enriched language learning context by drawing explicit linkage } \\
\text { between theory and practice so that learners find the pedagogical application. }\end{array}$ \\
\hline Time on task & $\begin{array}{l}\text { As much as possible should be spent focusing on reflective tasks to foster learners' } \\
\text { intellectual ability. }\end{array}$ \\
\hline Depth of processing & $\begin{array}{l}\text { ELT materials should help learners process the course content thoughtfully (develop their } \\
\text { critical literacy) by in-depth analysis of the discussed topic. }\end{array}$ \\
\hline $\begin{array}{l}\text { Integr } \\
\text { Motiv }\end{array}$ & $\begin{array}{l}\text { ELT materials should integrate both social development and language skill development to } \\
\text { go beyond the understanding of the texts. }\end{array}$ \\
\hline Leari & earning materials in ways that most suit their culture, society, and learning style. \\
\hline B & EQUENCING \\
\hline Frequ & Contents should be negotiated with the best poss \\
\hline $\begin{array}{l}\text { Strategies and } \\
\text { autonomy }\end{array}$ & Materials should help learners become self-directed through contextualization \\
\hline Spaced retrieval & $\begin{array}{l}\text { ELT materials should provide repeated opportunities for learners to retrieve information } \\
\text { from authentic materials. }\end{array}$ \\
\hline Language system & $\begin{array}{l}\text { The language focus should speed up both collective social transformation and cognitive } \\
\text { development. }\end{array}$ \\
\hline Keep moving forward & $\begin{array}{l}\text { ELT material should progressively help learners develop critical awareness of their own } \\
\text { sociopolitical context. }\end{array}$ \\
\hline Teachability & Teaching is a cycle of reflection and action by embracing learners' critical needs analysis. \\
\hline Learning burden & Materials should help learners challenge their own assumptions concerning the course. \\
\hline Interference & $\begin{array}{l}\text { ELT materials should sequence from more familiar to less familiar hidden curriculum by } \\
\text { incorporating learners' background experience into the new context. }\end{array}$ \\
\hline C & MONITORING AND ASSESSMENT \\
\hline $\begin{array}{l}\text { Ongoing needs \& } \\
\text { environment analysis }\end{array}$ & $\begin{array}{l}\text { Both students' critical language awareness and their linguistic skills should be evaluated } \\
\text { through alternative assessment. }\end{array}$ \\
\hline Feedback & Learners should receive implicit feedback that allows them to develop critical thinking. \\
\hline Teacher role & Materials should take into account teacher as co-learner, coordinator, and a problem poser. \\
\hline Student role & Students are active decision makers who participate in assessing their performance. \\
\hline
\end{tabular}

